ARTICLE

\title{
Conceptual Radiation Shielding Design of Superconducting Tokamak Fusion Device by PHITS
}

\author{
Atsuhiko M. SUKEGAWA ${ }^{1, *}$, Hiromitsu KAWASAKI ${ }^{2}$ and Koichi OKUNO ${ }^{3}$ \\ ${ }^{1}$ Japan Atomic Energy Agency, Naka-shi, Ibaraki 311-0193, Japan \\ ${ }^{2}$ Itochu Techno-Solutions Corporation, Chiyoda-ku, Tokyo 100-6080, Japan \\ ${ }^{3}$ Hazama Technical Research Institute, Tsukuba-shi, Ibaraki 305-0822, Japan
}

\begin{abstract}
A 3D neutron and photon transport analysis by Monte Carlo transport code system PHITS (Particle and Heavy Ion Transport code System) has been performed for superconducting tokamak fusion device such as JT-60 Super Advanced (JT-60SA). It is possible to make use of PHITS in the port streaming analysis around the devices for the tokamak fusion device, the duct streaming analysis in the building where the device is installed, and the sky shine analysis for the site boundary. The neutron transport analysis by PHITS makes it clear that the shielding performance of the superconducting tokamak fusion device with the cryostat has been improved by the graphical results. From the standpoint of the port and duct streaming, it is necessary to estimate by 3D Monte Carlo code such as PHITS for the neutronics analysis of superconducting tokamak fusion device.
\end{abstract}

KEYWORDS: radiation shielding design, superconducting coil, tokamak fusion device, JT-60SA, PHITS,

Monte Carlo

\section{Introduction}

PHITS (Particle and heavy Ion Transport code System) ${ }^{1)}$ is a 3D Monte Carlo transport code system for all particles of neutron, photon, proton, hadron, nucleus, electron and Heavy ions up to $200 \mathrm{GeV}$. The system is able to deal with lower than $20 \mathrm{MeV}$ neutron and low energy photon and electron transport based on evaluated nuclear data library with the same geometry data as MCNP code. ${ }^{2,3)}$

It is important to evaluate the nuclear responses such as the radiation shielding, nuclear heating, induced activity and dose rate in various locations within the building. The nuclear responses on radiation shielding design has been performed by mainly SN methods such as $1 \mathrm{D} \mathrm{ANISN}^{4)}$ code and 2D DOT3.5 code. ${ }^{5)}$ Unfortunately, these methods have the disadvantages of Ray Effect on SN methods to estimate the streaming around the device. ${ }^{6,7)}$

In an advanced deuterium-deuterium (DD) fusion device as Superconducting fusion tokamak device: JT-60SA (JT-60 Super Advanced) will be constructed in the existing JT-60 facilities and be operated for more than ten years with DD discharges. The annual neutron emission from the steady state plasma will increase by about fifty times the permitted amount of neutron emission in the JT-60U (JT-60 Upgrade) device. Hence, the neutron emitted by JT-60SA must be shielded more effectively in the vacuum vessel, the cryostat and the JT-60 building.

In particular, it is necessary to improve the neutron shielding performance using the vacuum vessel of JT-60SA. For JT-60SA, however, the water layer thickness of vacuum ves-

*Corresponding author, E-mail:morioka.atsuhiko@jaea.go.jp sel is limited to $135 \sim 150 \mathrm{~mm}$ as specified by the size of TF superconducting coil in which $\mathrm{NbTi}$ winding is newly used. The radiation shielding performance of the vacuum vessel by using pure water was insufficient, so that we selected the water with boric acid, namely borated water, instead of pure water. The thickness of the borated water layer $140 \mathrm{~mm}$ was adopted from the radiation shielding design of toroidal field magnetic (TF) superconducting winding by 1D calculation and $2 \mathrm{D}$ calculation on the conceptual design. ${ }^{8)}$

In the present radiation shielding design, the radiation shielding concepts of JT-60SA are entrusted by mainly the vacuum vessel and the cryostat due to the restricted space in the building. From the 3D neutron and photon transports analysis, it was clarified that the effects of neutrons by the port streaming of the JT-60SA are clearly depicted in JT-60 torus hall. So, the radiation shielding conceptual design of superconducting tokamak device such as JT-60SA not only consider the structure of the vacuum vessel and the cryostat, but also have to assess the effect of the port streaming by the 3D neutron and photon transport analysis with PHITS.9)

In this paper, we discuss the neutron and the photon transport analysis with the effects of the streaming and the additional shielding by PHITS for the conceptual radiation shielding design of superconducting tokamak fusion device such as JT-60SA. The objectives are to investigate the availability and the advantage of PHITS for the shielding design of superconducting tokamak fusion device.

\section{Radiation Shielding Design}

Figure 1 shows for the radiation safety on superconducting tokamak fusion device, it is important to resolve the 


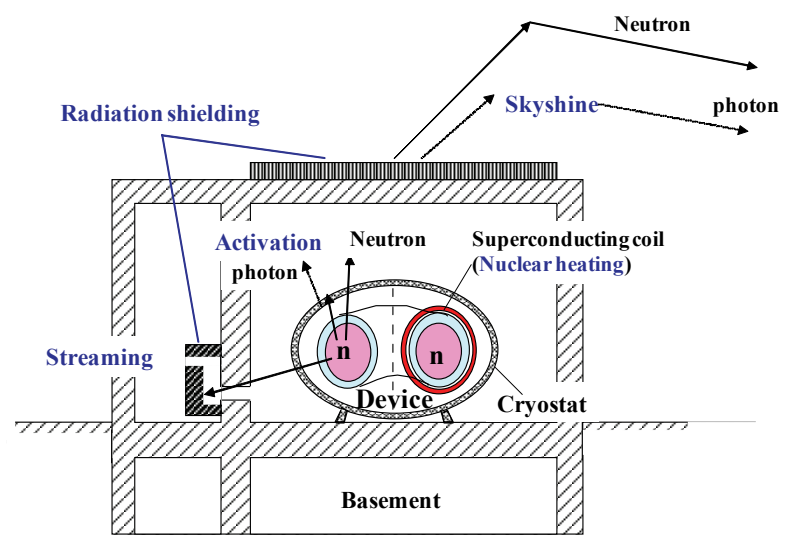

Fig. 1 Nuclear Responses on Superconducting Tokamak Fusion Device

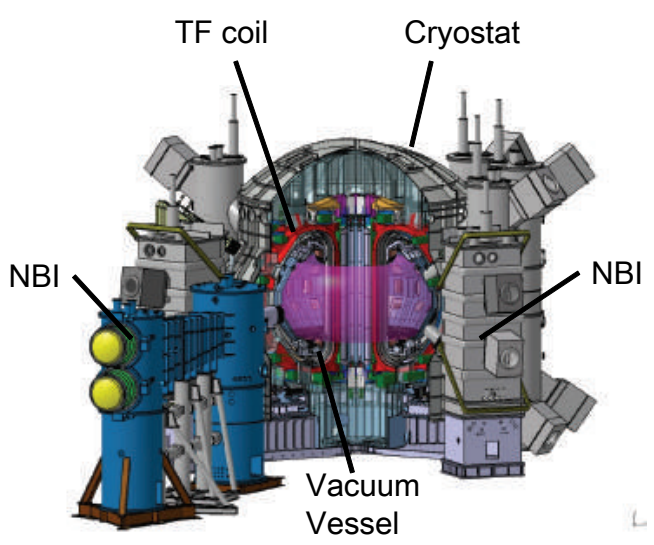

Fig. 2 Bird's view on Superconducting Tokamak Fusion Device

nuclear responses into the following points: (1) estimation of biological shielding during the operation; (2) estimation of the dose rate by the activation in areas required to access after the operation; (3) the safe operation of the superconducting coil during the operation.

Figure 2 shows neutrons by the DD fusion reaction in the plasmas are emitted from the vacuum vessel and the cryostat in Superconducting tokamak fusion device. The NBI (Neutral Beam Injector) and RF (Radio Frequency) heating system and the diagnostic system are arranged in surroundings of the cryostat.

Figure 3 shows the JT-60 building shielded by the $2,000 \mathrm{~mm}$ thick ordinary concrete on the ceiling by the shielding materials composed on the ceiling of concrete panels of $500 \mathrm{~mm}$, polyethylene of $150 \mathrm{~mm}$ and the concrete of $150 \mathrm{~mm}$ thicknesses. The JT-60 torus hall and the assembly hall are partitioned with the additional polyethylene shielding material (Y3 wall) of $0.35 \mathrm{~m}$ thickness. In addition, the first floor of JT-60 torus hall and the B1 floor are partitioned with the $2 \mathrm{~m}$ thickness concrete. Moreover, the first floor of the JT-60 torus hall has the duct for the piping and the cable of 40 places.

Table 1 shows the neutron emission rates of JT-60U and JT-60SA. The neutron emission rates from the JT-60SA plasma will be planned to increase the permitted rates in the

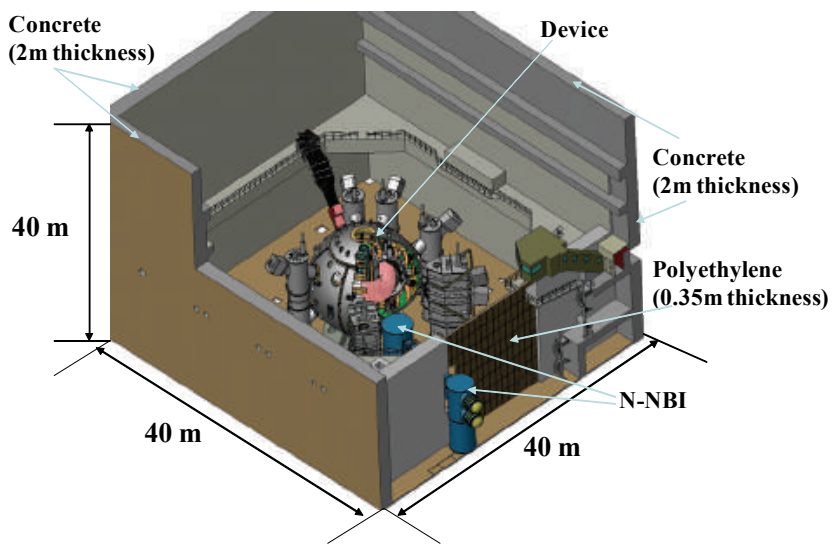

Fig. 3 Shielding structure of JT-60 building

Table 1 Neutron emission rates of JT-60U and JT-60SA

\begin{tabular}{|c|c|c|c|}
\hline Neutron Emission Rates & $\begin{array}{l}\text { JT-60SA } \\
\text { Expected }\end{array}$ & $\begin{array}{c}\text { JT-60U } \\
\text { Permitted }\end{array}$ & JT-60SA/JT-60U \\
\hline nisec & $4,0 \times 10^{17}$ & $2.0 \times 10^{17}$ & 2.0 \\
\hline niwuek & $2.5 \times 10^{20}$ & $3.1 \times 10^{18}$ & 80.6 \\
\hline $\mathrm{n} / 3$ months & $1.0 \times 10^{21}$ & $2.7 \times 10^{16}$ & 47.6 \\
\hline ryeat & $1.5 \times 10^{21}$ & $3.1 \times 10^{19}$ & 48.4 \\
\hline
\end{tabular}

JT-60U. The improvement of the shielding performance of JT-60SA are entrusted by mainly the vacuum vessel and the cryostat as an additional shielding for the compact shielding concept due to the restricted space in the building.

The structure of the vacuum vessel and the cryostat is possible to be simplified. For safe operation of the superconducting TF coils, the vacuum vessel is required to suppress the nuclear heating at the TF coil.

\section{Vacuum Vessel Design}

At first, the vacuum vessel of the JT-60SA was designed by the double-wall structure with pure water to shield the neutrons. To improve the thermal neutron shielding performance for reducing the air activation in the building, we select the borated water. The solubility to the pure water of boric acid $\left(\mathrm{H}_{3} \mathrm{BO}_{3}\right)$ is about $8 \sim 20 \mathrm{wt} \%$ at $40 \sim 80{ }^{\circ} \mathrm{C}$ of the water temperature. ${ }^{10)}$ In addition, the concentration ratio of ${ }^{10} \mathrm{~B}(20 \%$ in nature $)$ in the borated water is enriched up to $95 \%$. Considering shielding effect of the cryostat for biological shielding in the torus hall, the $40{ }^{\circ} \mathrm{C}$ borated water $(95 \%$ ${ }^{10} \mathrm{~B}$ enriched) as the shielding material is adopted to initial JT-60SA shielding design. The structure consists of double wall using the $24 \mathrm{~mm}$ thickness of SS316L filled with the $140 \mathrm{~mm}$ (inboard) of the borated water. ${ }^{8}$

In the shielding design by borated water, the borated water needs the temperature management of the plant. As a decrease plan of capital investment on the plant, the design without the management of the borated water is demanded. The shielding performance of the vacuum vessel by borated water and pure water as the shielding material are assessed. ${ }^{8)}$

The neutron and gamma-ray fluxes during the operation are calculated with the ANISN code. ${ }^{4}$ The calculation model of the toroidal cylindrical geometry was used. A transport group constant set, which consists of 42 neutron groups and 


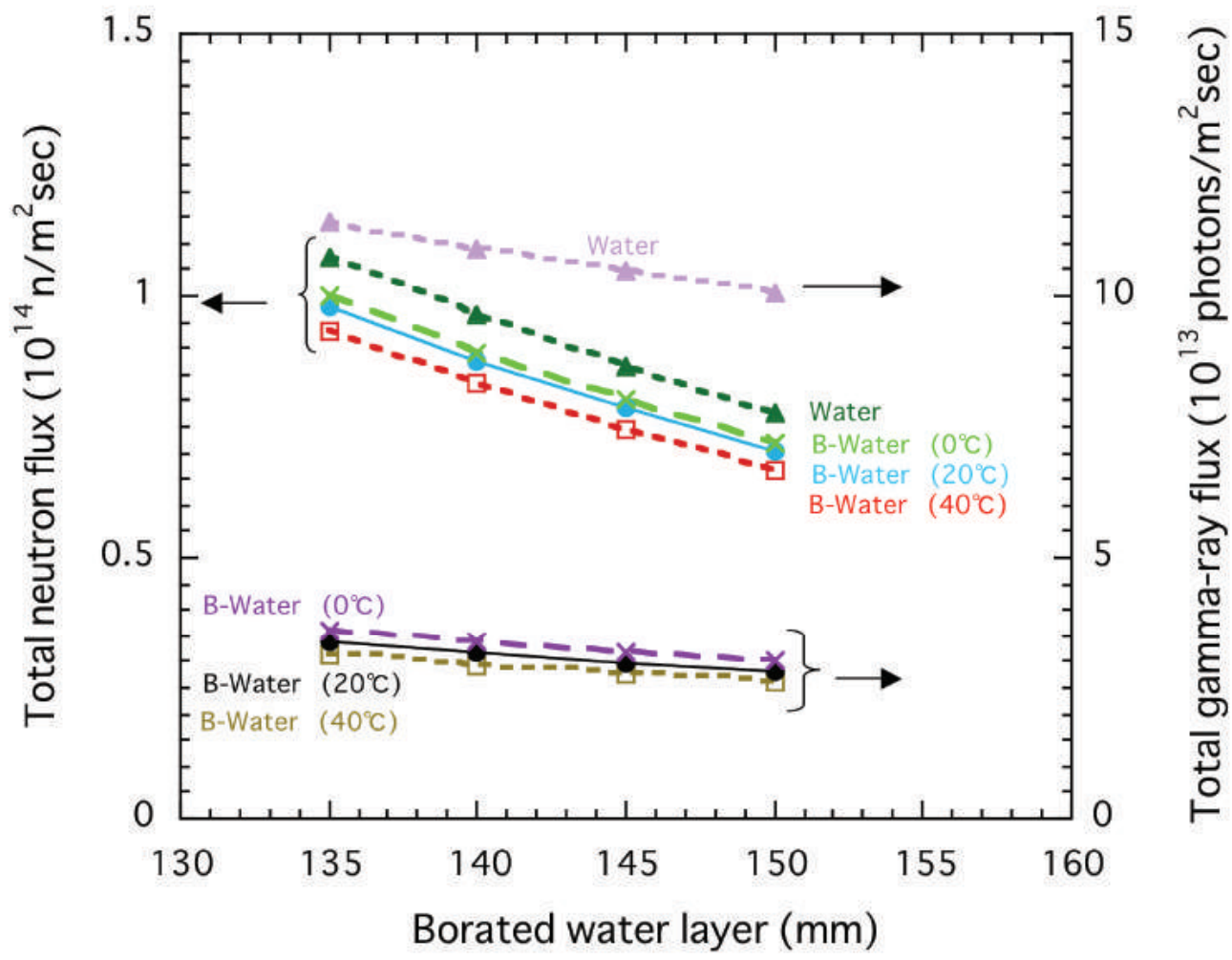

Fig.4 Total neutron and total gamma-ray flux through the vacuum vessel.

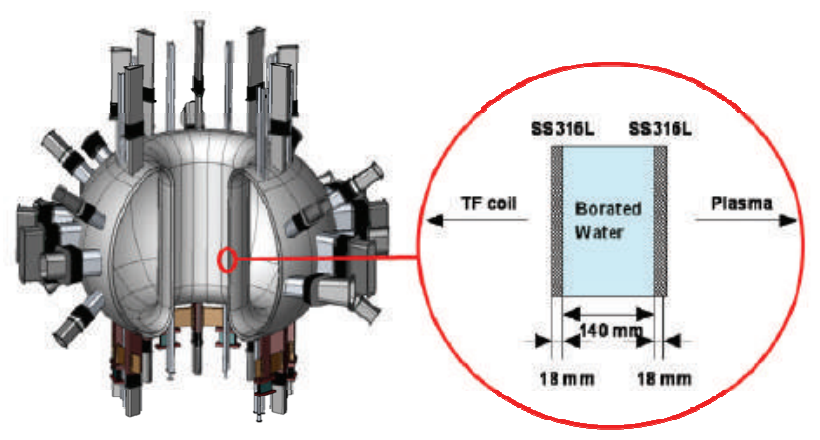

Fig. 5 Vacuum vessel and the structure

21 gamma-ray groups based on JENDL-3.3 ${ }^{11)}$ is used in the code.

Figure 4 shows the calculated total neutron flux and total gamma-ray flux dependence through the water layer $(135 \sim 150 \mathrm{~mm})$ of the double-wall structure. The cross, circle and square symbols indicate the total fluxes with $0{ }^{\circ} \mathrm{C}$ borated water, $20^{\circ} \mathrm{C}$ borated water and $40^{\circ} \mathrm{C}$ borated water, respectively. The triangle symbol indicates the total fluxes with pure water. The total neutron flux through the $40{ }^{\circ} \mathrm{C}$ borated water decreases with the borated water layer, and is about $6.5 \%$ smaller than that through the $0{ }^{\circ} \mathrm{C}$ borated water. The total neutron flux through the pure water is about 3.4 times larger than that through the $40^{\circ} \mathrm{C}$ borated water. The total gamma-ray flux through the vacuum vessel decreases with the borated water layer. The total gamma-ray flux through the $40{ }^{\circ} \mathrm{C}$ borated water is about $13.6 \%$ smaller than that of $0{ }^{\circ} \mathrm{C}$. The total gamma-ray flux through the pure wa-
Table 2 Radiation Shielding Design of JT-60SA

\begin{tabular}{cccc}
\hline & $\begin{array}{c}\text { Dose rate at } \\
\text { boundary of } \\
\text { controlled area }\end{array}$ & $\begin{array}{c}\text { Dose rate out- } \\
\text { side of cryostat } \\
\text { (3days cooling) }\end{array}$ & $\begin{array}{c}\text { Dose rate at } \\
\text { boundary of site }\end{array}$ \\
\hline $\begin{array}{c}\text { Legal } \\
\text { limit }\end{array}$ & $\begin{array}{c}1.3 \mathrm{mSv} / 3 \\
\text { months }\end{array}$ & - & $\begin{array}{c}250 \mu \mathrm{Sv} / 3 \\
\text { months }\end{array}$ \\
\hline $\begin{array}{c}\text { Design } \\
\text { target }\end{array}$ & - & $\sim 10 \mu \mathrm{Sv} / \mathrm{hour}$ & $50 \mu \mathrm{Sv} /$ year \\
\hline
\end{tabular}

ter is about 3.7 times larger than that of $40{ }^{\circ} \mathrm{C}$ borated water. The shielding method by the pure water increases the gamma-rays. It was clarified that the shielding performance is a little on the difference of the temperature of the borated water.

Based on these simplified transport calculations, the nuclear heating of the coil that considered the effects of the port streaming of vacuum vessel has been estimated by 3D neutronics analysis for the safe operation of the superconducting coil during the operation. ${ }^{12)}$ Therefore, Figure 5 shows the structure consisted of double wall using the $18 \mathrm{~mm}$ thickness of SS316L filled with the $140 \mathrm{~mm}$ thick borated water.

\section{Cryostat Design}

The purposes of the shielding structure are as follows: (i) biological shield for human safety, (ii) reduction of radioactive nuclide contents in air, and (iii) thermal shielding of the superconducting coil. Table 2 shows legislative upper limits and JT-60SA radiation design values. Figure 6 shows the neutron fluxes and the total gamma-ray flux on the 1D model of JT-60SA. 


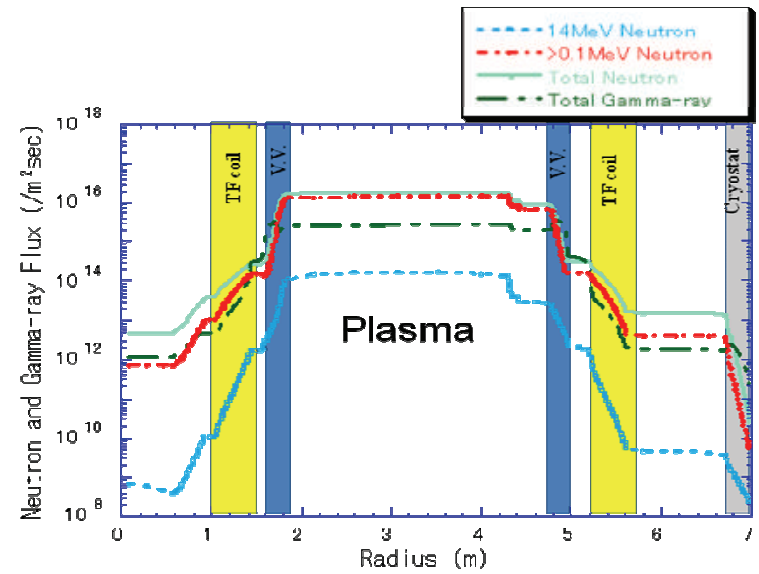

Fig. 6 Neutron and photon transport analysis by cylindrical model

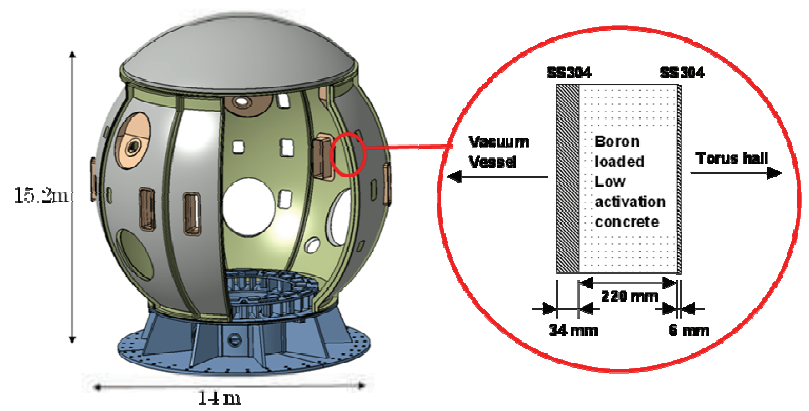

Fig. 7 Cryostat and the structure (Model A: Fig. 8(a))

In the basic structure design using $1 \mathrm{D}$ code of the cryostat for the demanded neutron yields $\left(1.5 \times 10^{21} \mathrm{n}\right.$ /year as the maximum), the dose rate at the surface of the cryostat was decided to secure the acceptance for maintenance workers using a novel boron-loaded low activation concrete. Figure 7 shows the cryostat consists of the $220 \mathrm{~mm}$ thickness of the concrete between two SS304 panels of $34 \mathrm{~mm}$ (inboard) and $6 \mathrm{~mm}$ (outboard) thicknesses. The low activation concrete contaminated with $\mathrm{B}_{4} \mathrm{C}$ (Boron: $2 \mathrm{wt} \%$ ) is adopted to improve the shielding efficiency of the thermal neutrons through the vacuum vessel. ${ }^{13)}$

\section{Calculation}

$3 \mathrm{D}$ radiation shielding analysis has been carried out in order to assess the detailed information on radiation environment JT-60SA device with the building in the JT-60 facilities. The calculation has been carried out using $3 \mathrm{D}$ Monte Carlo code PHITS-2.13 with JENDL-3.3 $3^{14)}$ as evaluated nuclear data libraries of ENDF format.

The PHITS has been improved for the analysis of the tokamak fusion device. The mono-energetic neutrons $\left(\mathrm{E}_{\mathrm{n}}=\right.$ $2.45 \mathrm{MeV}$ ) of the DD fusion devices are used for the neutron source in the analysis. A neutron source that imitates the shape of tokamak plasma in PHITS has been replaced by a newly developed source program. The plasma parameters are shown as follows: $R_{p}$ is the major radius $(=303.15 \mathrm{~cm})$, $\mathrm{a}_{\mathrm{p}}$ is the minor radius $(=115.15 \mathrm{~cm}), \mathrm{Z}_{\mathrm{p}}$ is the vertical shift of the plasma center $(=0.0), \kappa$ is the ellipticity $(=1.91){ }^{9}{ }^{9}$

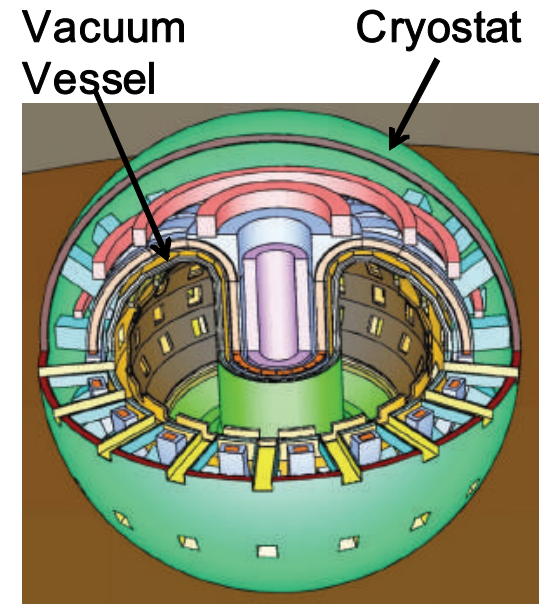

Fig. 8 (a) 3D model plot of device (Model (A))

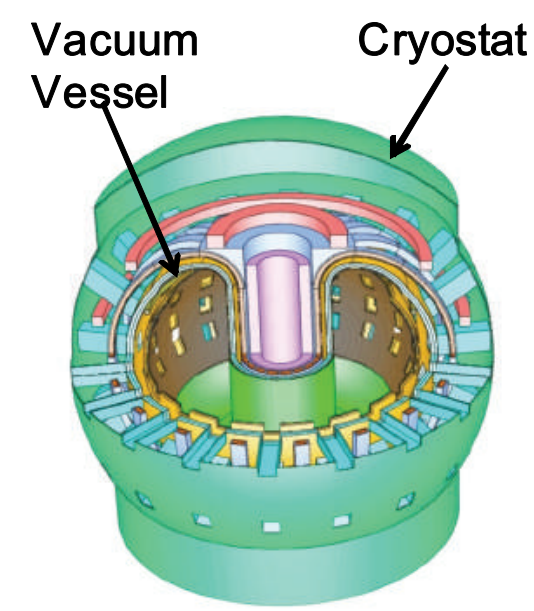

Fig. 8 (b) 3D model plot of device (Model (B))

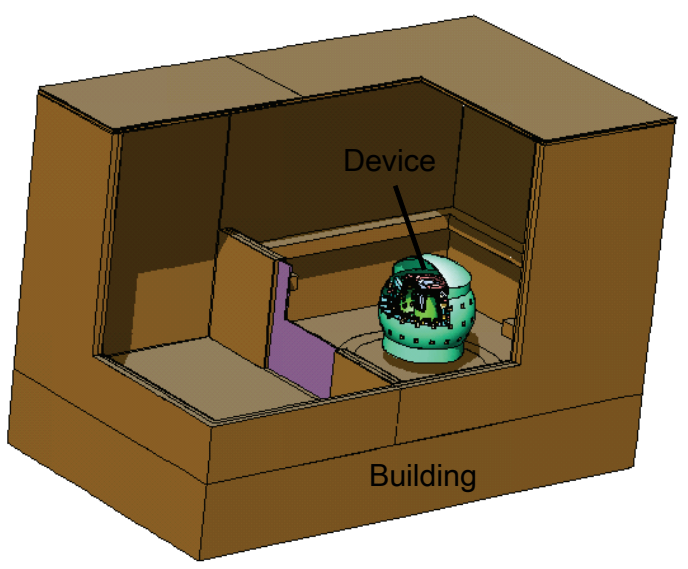

Fig. 8 (c) 3D model plot of the building with the device (Model (B))

The visual representation of nuclear responses such as the neutron flux distribution and the photon flux distribution around the devices, inside the JT-60 building and the sky shine of the site has been calculated by PHITS for the fusion tokamak device.

Figure 8 shows the graph transformed the input geometry data for the analysis into the bird's-eye view by PHITS. 


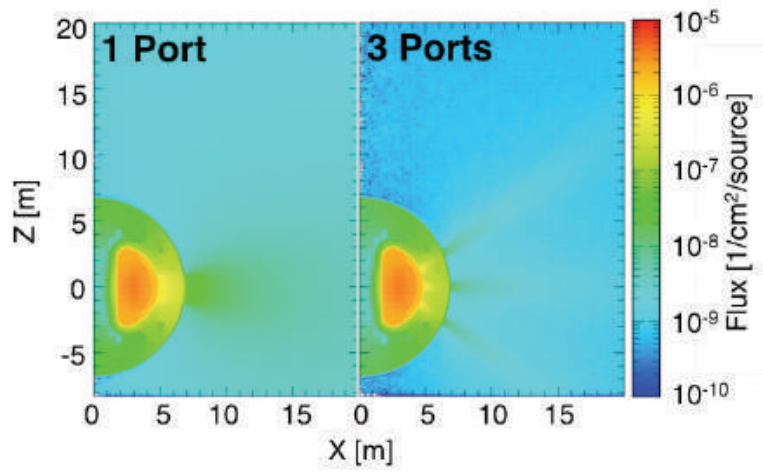

Fig. 9 Total neutron flux distribution obtained from neutron transport analysis of port streaming analysis

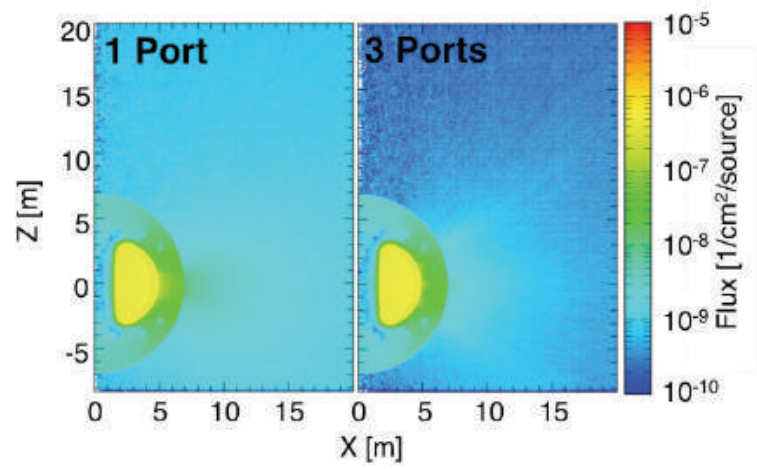

Fig. 10 Total gamma-ray flux distribution obtained from gamma-ray transport analysis of port streaming analysis

\section{Results and Discussion}

\section{Neutron and Photon Transport Analysis}

In comparison of the total neutron flux distributions on JT-60SA, Figure 9 shows the poloidal cross sections of 1 port opened model and 3 ports opened model of JT-60SA device in the torus hall at $2 \mathrm{D}(\mathrm{X}-\mathrm{Z})$ plane plain.

In comparison of the total neutron flux distributions on 1 port opened model and 3 ports opened model of JT-60SA, the PHITS analysis makes it clear that the neutron shielding performance of 3 ports opened model of JT-60SA is improved by the vacuum vessel and the cryostat.

The neutron leakage from the large port $\left(2.0 \times 0.6 \mathrm{~m}^{2}\right)$ such as for the maintenance by remote handling and the three ports (upper port: $0.55 \times 0.52 \mathrm{~m}^{2}$, middle port: $0.6 \times$ $0.5 \mathrm{~m}^{2}$, lower port: $0.55 \times 0.52 \mathrm{~m}^{2}$ ) such as for the additional heating systems or the diagnostics at the cryostat was vividly analyzed on the JT-60SA. On JT-60SA operation, however, it is not easy to shield the port for the heating (3 Ports) though the remote handling port (1 Port) is shielded by an additional shielding material.

The phenomenon such as Ray Effect on the port streaming analysis using discrete ordinate methods was not observed as a characteristic on the PHITS analysis. In these estimations, the influence of the port streaming is improved by the surrounding of the JT-60 building. The emitted fusion neutrons by the port streaming are scattered and absorbed in the concrete building. The thermalized neutrons will be filled in the building.

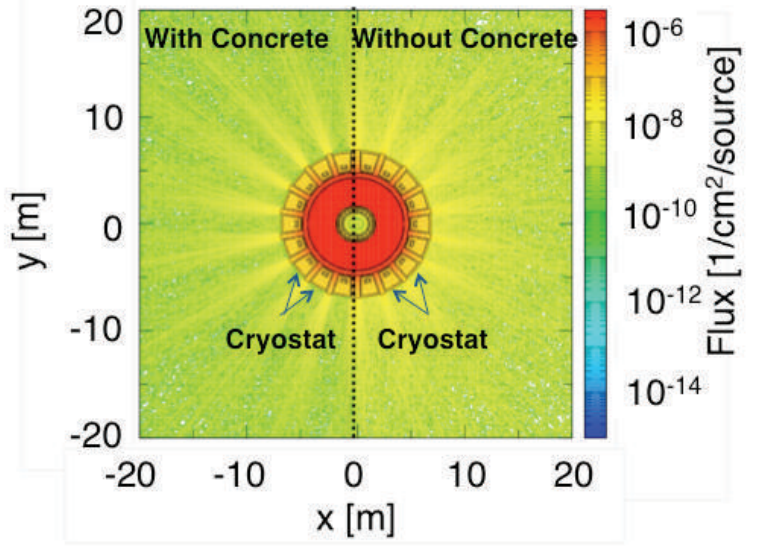

Fig. 11 Total neutron flux distribution

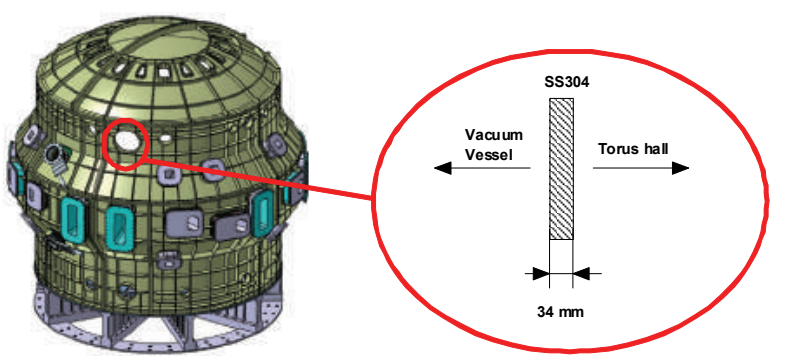

Fig. 12 Cryostat and the structure (Model B: Fig. 8(b))

Figure 10 shows the total gamma-ray flux distributions of the poloidal cross ssssections of 1 port opened model and 3 ports opened model of JT-60SA device in the torus hall at 2D (X-Z) plane.

In comparison of the total gamma-ray flux distributions on these models of JT-60SA, the total gamma-ray flux is two order smaller than the total neutron fluxes of Fig. 9.

In addition, Fig. 11 shows the total neutron distribution at 2D (X-Y) mid-plane around the device with/without the concrete of the cryostat on Fig. 7. From the calculation results of the toroidal view, it was clarified that the effects of neutrons by the port streaming from the cryostat of the JT-60SA device to JT-60 torus hall are clearly depicted. So, the conceptual radiation shielding design of superconducting tokamak fusion device such as JT-60SA not only consider the structure of the vacuum vessel and the cryostat but also have to assess the effect of the port streaming by $3 \mathrm{D}$ codes.

As for the role as cryostat, it was clarified that the effect is a little to bio-shielding of the cryostat using $3 \mathrm{D}$ analysis. Therefore, the radiation shielding design of the cryostat has been changed to the lightened design no using the concrete such as Fig. 12. Figure 13 shows the cross sectional view of the old design and the refined design on Superconducting Tokamak Fusion Device.

\section{Effect of Radiation Streaming}

Figure 14 shows the total neutron flux and the total gamma-ray flux distribution described at 2D (R-Z) plane in JT-60 torus hall by PHITS analysis of the JT-60SA. From the analysis, it was clarified that the effects of the neutron 


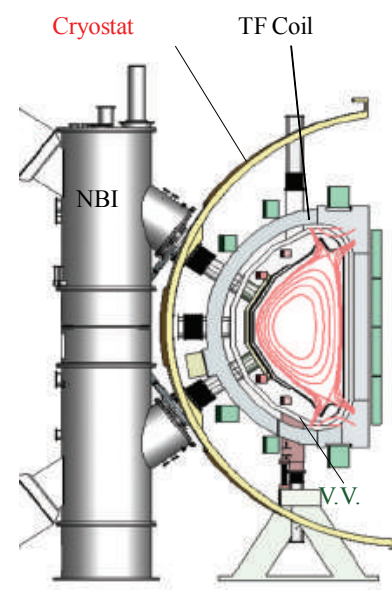

Old design

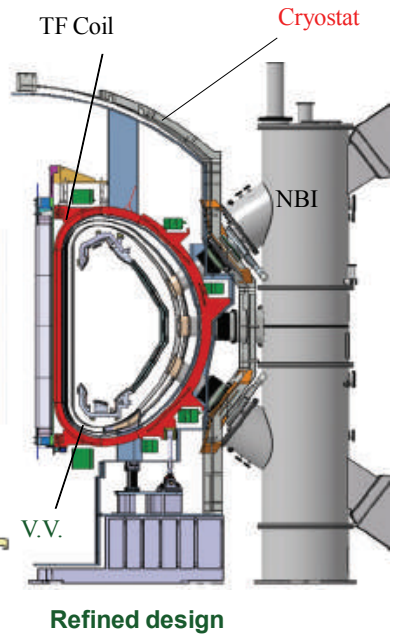

Refined design
Fig. 13 Cross sectional view of superconducting tokamak fusion device

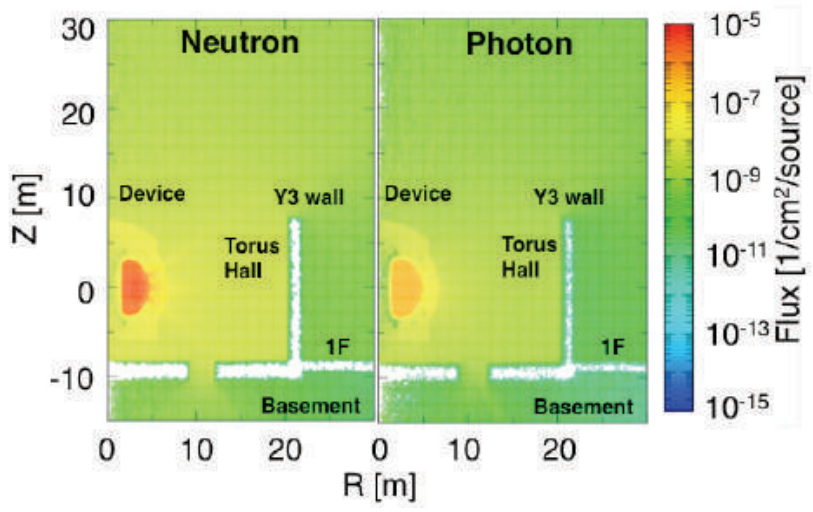

Fig. 14 Neutron and photon transport analysis results in JT-60 building

and the photon by the port and duct streaming with the additional shielding wall (Y3 wall) are clearly depicted in the JT- 60 torus hall of the JT- 60 building. The influence of the streaming is improved in a place away from the device though the total neutron flux level on the device peripheral is about two orders as high as surrounding of the building. We are not using the variance reduction technique such as weight window methods in all numerical results.

To assess the influence on the dose rate by the difference of the neutron flux with port and duct streaming with the Y3 wall, the dose rate of various points in JT-60 building has been evaluated during the DD operation of JT-60SA by the PHITS analysis. The DD neutron emission rate for the estimation of the dose rate is $2.5 \times 10^{20} \mathrm{n} /$ week. Figure 15 shows the various estimation points (A-F) in JT-60 building.

Point $A$ is the wall in side JT-60 torus hall $(\mathrm{R}=20 \mathrm{~m}$, $\mathrm{Z}=5 \mathrm{~m}$ ). Point $\mathrm{B}$ is the duct toward $\mathrm{B} 1$ of JT- 60 building $(\mathrm{R}=10.6 \mathrm{~m}, \mathrm{Z}=-12 \mathrm{~m})$. Point $\mathrm{C}$ is under the ceiling in JT-60 building $(\mathrm{R}=20 \mathrm{~m}, \mathrm{Z}=31.9 \mathrm{~m})$. Point $\mathrm{D}$ is the wall outside torus hall $(\mathrm{R}=22 \mathrm{~m}, \mathrm{Z}=5 \mathrm{~m})$. Point $\mathrm{E}$ is outside the neutron shielding door $(\mathrm{R}=33 \mathrm{~m}, \mathrm{Z}=0 \mathrm{~m})$. Point $\mathrm{F}$ is $\mathrm{B} 1$ floor ( $\mathrm{R}=52.3 \mathrm{~m}, \mathrm{Z}=-16.5 \mathrm{~m})$.

The code is used for evaluating dose rate in the JT-60

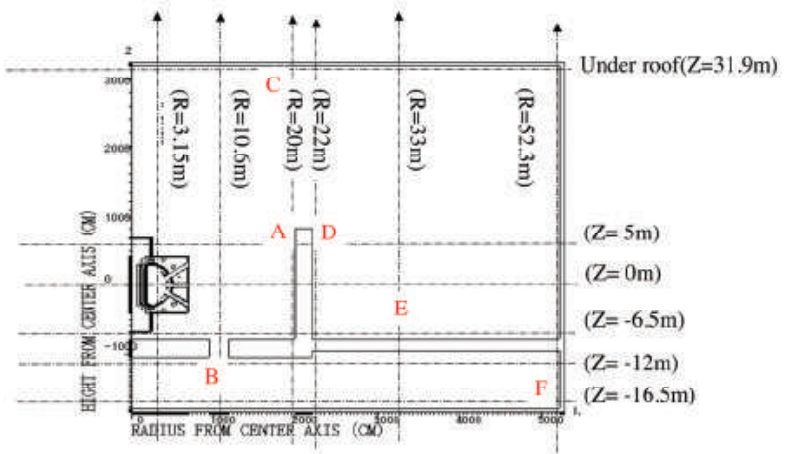

Fig. 15 Conceptual estimation points in JT-60 building

Table 3 Normalized dose rate of the various points in JT-60 building

\begin{tabular}{|c|c|c|c|c|}
\hline & $\begin{array}{c}\text { Estimation } \\
\text { Point }\end{array}$ & \begin{tabular}{|c|}
$\begin{array}{c}\text { Borated Water } \\
\left(40^{\circ} \mathrm{C}\right)\end{array}$ \\
\end{tabular} & \begin{tabular}{|c|} 
Borated Water \\
$\left(0^{\circ} \mathrm{C}\right)$ \\
\end{tabular} & Pure Water \\
\hline \multirow{6}{*}{ Neutron Dose } & $\mathrm{A}$ & 1.00 & 1.27 & 1.26 \\
\hline & $\mathrm{B}$ & 1.00 & 1.28 & 1.21 \\
\hline & $\mathrm{C}$ & 1.00 & 1.30 & 1.41 \\
\hline & $\mathrm{D}$ & 1.00 & 1.13 & 1.26 \\
\hline & $\mathrm{E}$ & 1.00 & 1.21 & 1.28 \\
\hline & $\mathrm{F}$ & 1.00 & 1.30 & 1.19 \\
\hline \multirow{6}{*}{ Gamma-ray Dose } & $\mathrm{A}$ & 1.00 & 1.03 & 1.61 \\
\hline & $\mathrm{B}$ & 1.00 & 0.97 & 1.05 \\
\hline & $\mathrm{C}$ & 1.00 & 1.02 & 1.79 \\
\hline & $\mathrm{D}$ & 1.00 & 1.09 & 1.10 \\
\hline & $\mathrm{E}$ & 1.00 & 1.04 & 1.10 \\
\hline & $\mathrm{F}$ & 1.00 & 1.07 & 1.09 \\
\hline \multirow{6}{*}{ Total Dose } & $\mathrm{A}$ & 1.00 & 1.26 & 1.27 \\
\hline & $\mathrm{B}$ & 1.00 & 1.27 & 1.21 \\
\hline & $\mathrm{C}$ & 1.00 & 1.29 & 1.43 \\
\hline & $\mathrm{D}$ & 1.00 & 1.13 & 1.25 \\
\hline & $\mathrm{E}$ & 1.00 & 1.20 & 1.27 \\
\hline & $\mathrm{F}$ & 1.00 & 1.27 & 1.18 \\
\hline
\end{tabular}

building. Neutron and gamma-ray spectrum at the estimation point has been calculated by the track length tally of the code. Neutron dose, Gamma-ray dose and Total dose of the various points are calculated by using the spectrums and the ICRP Pub.74 dose conversion factor. ${ }^{15}$

Table 3 shows neutron, gamma and total dose rate at the various points in the JT-60 building in case of the borated water $\left(40^{\circ} \mathrm{C}, 0^{\circ} \mathrm{C}\right)$ and the pure water as the neutron shielding materials filled in the vacuum vessel. Each value is normalized by the dose rate of borated water $\left(40^{\circ} \mathrm{C}\right)$.

The total dose rate at the estimation points by pure water are larger about $1.2 \sim 1.4$ times than that of the borated water $\left(40^{\circ} \mathrm{C}\right)$.

According to the ICRP dose rate conversion factor, it seems likely that the contribution to dose rates by fast neutrons is roughly dominant. So, the influence on dose rate is small by changing the borated water temperature which directly affects thermal neutrons.

\section{Skyshine Analysis}

To assess the influence on neutron and photon transport on the site boundary, a skyshine analysis by PHITS has been performed by using $3 \mathrm{D}$ model with the plasma neutron source of plasma shape, the device, the port of device, the 


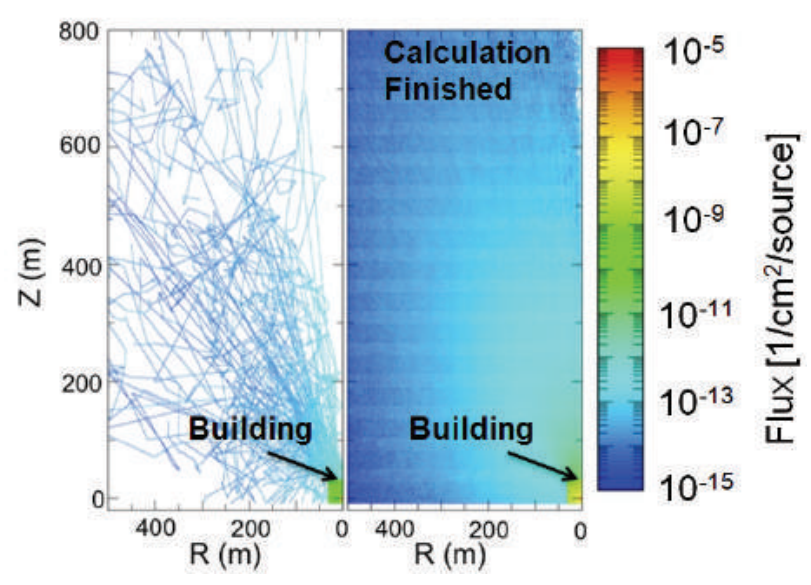

Fig. 16 Total gamma-ray flux distribution obtained from skyshine analysis on the JT-60 facility

duct of building and the building. Figure 16 shows the gamma-ray flux distribution by the analysis.

On DD neutron penetration, the influence with secondary gamma rays cannot be disregarded compared with the influences by the penetration of the neutron when normal concrete thickness and polyethylene thickness exceeds about $1.2 \mathrm{~m}$ and $0.3 \mathrm{~m}$, respectively.

The site boundary of JT-60 facility is $405 \mathrm{~m}$ at the maximum (R-Z direction). From the 3D analysis, it was clarified the effects of gamma-ray radiation by the shielding material of polyethylene on the ceiling of the JT- 60 building with the operation.

\section{Conclusion}

A complete 3D radiation shielding analysis by PHITS has been performed for the Superconducting Tokamak Fusion Device.

It is possible to make use of PHITS in the streaming analysis around the devices for the tokamak fusion device and the sky shine analysis for the site boundary. The neutron transport analysis by PHITS makes it clear that the shielding performance of the superconducting tokamak fusion device (JT-60SA) with the cryostat is improved by vacuum vessel and cryostat by the graphical results of the PHITS, and the effect of the port streaming of superconducting fusion tokamak device with the cryostat is crucial. From the standpoint of the port streaming and the duct streaming, it is necessary to calculate by $3 \mathrm{D}$ codes such as PHITS for the neutronics analysis of the superconducting tokamak fusion device.

In the near future, the completely 3D neutronics analysis of the additional heating system such as the NBI and the RF of the JT-60SA for the maintenance will be performed by the PHITS with the analysis codes for the activation estimation such as ACT-4. ${ }^{16,17)}$

\section{Acknowledgment}

The authors would like to thank the PHITS development team for these gained results.

\section{References}

1) H. Iwase, K. Niita, T. Nakamura, "Development of General-Purpose Particle and Heavy Ion Transport Monte Carlo Code," J. Nucl. Sci. Technol., 39, 1142-1151 (2002).

2) J. F. Briesmeister (ed.), MCNP - A General Monte Carlo $N$-Particle Transport Code Version 4C, LA-13709-M, Los Alamos National Laboratory (LANL) (2000).

3) X-5 Monte Carlo Team, MCNP-A General Monte Carlo N-Particle Transport Code, Version 5, LA-UR-03-1987, Los Alamos National Laboratory (LANL) (2003).

4) W. W. Engle, Jr., A User's Manual for ANISN, A One-dimensional Discrete Ordinates Transport Code with anisotropic Scattering, K-1693 (1967).

5) W. A. Rhoades et al., DOT3.5 Two-Dimensional Discrete Ordinates Radiation Transport Code, CCC-276 (1977).

6) K. Maki et al., "Radiation Shielding for superconductive toroidal field coils around the neutral beam injector duct in the ITER design," Fusion Eng. Des., 22, 427-434 (1993).

7) A. Morioka, A. Sakasai et al., "Evaluation of radiation shielding, nuclear heating and dose rate for JT-60 superconducting modification," Fusion Eng. Des., 63-64, 115-120 (2002).

8) A. M. Sukegawa, S. Sakurai et al., "Safety design of radiation shielding for JT-60SA," Fusion Eng. Des., 82, 2799-2804 (2007).

9) A. M. Sukegawa, K. Takiyoshi et al. , "Neutronic Anlysis of Fusion Tokamak Devices by PHITS," Prog. Nucl. Sci. Technol., 1, 36-39 (2011).

10) National Astronomical Observatory, chronological science tables 2009, Maruzen (2009).

11) K. Shibata et al., "Japanese Evaluated Nuclear Data Library, Version-3 - JENDL-3.3," J. Nucl. Sci. Technol., 39[11], 1125-1136 (2002).

12) R. Villari et al.," Neutronic analysis of the JT-60SA toroidal magnets," Fusion Eng. Des., 84, 1947-1952 (2009).

13) A. Morioka et al., "Irradiation and penetration tests of boron-doped low activation concrete using $2.45 \mathrm{MeV}$ and $14 \mathrm{MeV}$ neutron sources," J. Nucl. Mater., 329-333, 1619-1623 (2004).

14) K. Kosako et al., The Libraries FSXLIB and MATXSLIB Based on JENDL-3.3, JAERI-Data/Code 2003-011, Japan Atomic Energy Research Institute (JAERI) (2003).

15) International Commission on Radiological Protection, Conversion Coefficients for use in Radiological Protection against External Radiation, ICRP Publication 74, Ann. ICRP2 (3/4) (1998).

16) Y. Seki, H. Iida, H. Kawasaki, K. Yamada, THIDA-2: An Advanced Code System for Calculation of Transmutation, Activation, Decay Heat and Dose Rate, JAERI-1301, Japan Atomic Energy Research Institute (JAERI) (1986).

17) M. Yamauchi, J. Hori, S. Sato, T. Nishitani, C. Konno, H. Kawasaki, ACT-XN: Revised Version of an Activation Calculation Code for Fusion Reactor Analysis, JAEA-Data/Code 2007-016, Japan Atomic Energy Agency (JAEA) (2007). 